\title{
ABORDAGEM DE PACIENTES ADULTOS VÍTIMAS DE QUEIMADURAS
}

\section{ARTIGO DE REVISÃO}

CRUZ, Vinicius Gomes de Sales ${ }^{1}$, PARENTE, Débora Barbosa da Silva², BEM, Jéssica Cristina Corrêa ${ }^{3}$, RICARTE, João Pedro Barreto ${ }^{4}$, AZEVEDO, Juliana Fabricio de ${ }^{5}$, OLIVEIRA, Leticia Siqueira Vilela de ${ }^{6}$, MOURA, Maria Celina ${ }^{7}$, CARNEIRO, Maria Eduarda de Carvalho Penha ${ }^{8}$, VALE, Mariana Lima ${ }^{9}$, ZANLUQUI, $^{2}$ Natalia Uemura ${ }^{10}$, FONSECA, Sarah ${ }^{11}$, MOURA, Antônio Agostinho ${ }^{12}$

CRUZ, Vinicius Gomes de Sales. Et al. Abordagem de pacientes adultos vítimas de queimaduras. Revista Científica Multidisciplinar Núcleo do Conhecimento. Ano 06, Ed. 07, Vol. 11, pp. 171-189. Julho de 2021. ISSN: 2448-0959, Link de acesso: https://www.nucleodoconhecimento.com.br/saude/adultos-vitimas,

DOI: 10.32749/nucleodoconhecimento.com.br/saude/adultos-vitimas

\section{RESUMO}

Objetivo: Delinear, de maneira integrativa, as perspectivas de abordagem terapêutica de pacientes adultos vítimas de queimaduras. Métodos: Mediante utilização de fórmula de busca configurada a partir de descritores disponíveis nos Descritores em Ciências da Saúde, foram coletados12 artigos disponíveis no Portal Biblioteca Virtual de Saúde para análise criteriosa dos desfechos mais relevantes.

\footnotetext{
${ }^{1}$ Discente do curso de Medicina da Universidade do Sul de Santa Catarina.

2 Discente do curso de Medicina do Centro Universitário INTA - UNINTA.

${ }^{3}$ Discente do curso de Medicina da Universidade Privada del Este.

${ }^{4}$ Discente do curso de Medicina do Centro Universitário INTA - UNINTA.

${ }^{5}$ Discente do curso de Medicina da Faculdade de Ensino Superior da Amazônia Reunida.

${ }^{6}$ Discente do curso de Medicina da Universidade Municipal de São Caetano do Sul.

${ }^{7}$ Discente do curso de Medicina do Centro Universitário Presidente Tancredo de Almeida Neves.

${ }^{8}$ Discente do curso de Medicina do Centro Universitário do Maranhão.

${ }^{9}$ Discente do curso de Medicina do Centro Universitário INTA - UNINTA.

${ }^{10}$ Discente do curso de Medicina da Universidade Municipal de São Caetano do Sul.

${ }^{11}$ Discente do curso de Medicina da Faculdade de Ciências Médicas de Santos.

12 Orientador. Médico Cirurgião Plástico.
}

RC: 92268

Disponível em: https://www.nucleodoconhecimento.com.br/saude/adultos-vitimas 
Resultados: Dentre as abordagens analisadas, destaca-se a utilização de curativos biológicos e/ou formulados com colágeno hidrolisado a fim de catalisar processos de cicatrização e prevenir infecções de ferida. Cabe ressaltar, ainda, a utilização de tecido StrataGraft como alternativa ao autoenxerto e a regeneração epidérmica propulsionada pelo Sistema RECELL. No que concerne ao manejo farmacológico, inovações em tecnologia analgésica têm ganhado relevância no cenário emergencial. Conclusão: Perspectivas terapêuticas promissoras têm sido desenvolvidas com o fito de reduzir desfechos desfavoráveis durante a evolução clínica de pacientes vítimas de queimaduras.

Palavras-chave: Queimaduras, Unidade de Queimados, Terapêutica, Tratamento Multimodal.

\section{INTRODUÇÃO}

Queimadura, a primeira causa de lesão em adolescentes e adultos relacionada aos líquidos inflamáveis, é uma afecção decorrente da produção excessiva de calor que propicia danos teciduais e morte celular mediante ação de agentes térmicos, elétricos ou químicos. As repercussões desta lesão estão diretamente relacionadas à dimensão da resposta inflamatória à lesão e a sua profundidade e extensão. Dentre as principais etiologias, destacam-se as queimaduras pôr fogo ou chama, por líquidos quentes, por superfícies quentes, por eletricidade ou por produtos químicos em contato com a pele (AMERICAN COLLEGE OF SURGEONS, 2018; MINISTÉRIO DA SAÚDE, 2012; SOCIEDADE BRASILEIRA DE QUEIMADURAS, 2021).

As queimaduras podem ser classificadas quanto ao nível de profundidade da lesão, quais sejam: queimaduras de primeiro, segundo e terceiro graus. As primeiras, comumente eritemas solares, são classicamente superficiais, eritematosas, edemaciadas, dolorosas e atingem apenas a epiderme, descamando em 4 a 6 dias. As lesões de segundo grau, por sua vez, são superficiais ou de profundidade moderada e manifestam a formação de flictenas. Neste grau, as características da

RC: 92268

Disponível em: https://www.nucleodoconhecimento.com.br/saude/adultos-vitimas 
lesão correlacionam-se à profundidade (injúrias da epiderme evoluem com bolhas úmidas, de coloração rosada e caráter doloroso e danos alocados na derme manifestam-se com bolhas secas, pálidas, indolores ou pouco dolorosas), com reparo em 7 a 21 dias. Por fim, as queimaduras de terceiro grau, descritas como lesões profundas que abrangem a epiderme, a derme e podem atingir os tecidos subcutâneos, lesionam músculos e ossos. No que se refere à semiologia dermatológica, evidenciam textura coriácea e presença de placas que podem ser enegrecidas ou brancas. Em tais casos não há restauração da lesão, sendo necessário o tratamento hospitalar especializado, com indicação de enxertia de pele (GIORDANI et al., 2016; MINISTÉRIO DA SAÚDE, 2012).

É de suma importância caracterizar a lesão para determinar o melhor tratamento, assim como detectar a presença de lesões associadas. Tal identificação é baseada no tamanho, no tipo e na área do corpo acometida (SOCIEDADE BRASILEIRA DE QUEIMADURAS, 2021).

Queimaduras podem ser consideradas leves, com indicação de tratamento em domicílio, até lesões mais graves, que precisam de suporte hospitalar especializado. Como exemplo, queimaduras causadas por eletricidade, substâncias químicas, e por radioatividade devem ser encaminhados imediatamente para atenção terciária. Considera-se também, como queimado de grande gravidade, os pacientes, que tenham associado lesão inalatória, choque de qualquer origem, politrauma, diabetes, insuficiências renal, cardíaca e hepática, infarto agudo do miocárdio, embolia pulmonar, distúrbios da coagulação e hemostasia (SOCIEDADE BRASILEIRA DE CIRURGIA PLÁSTICA, 2008).

Em situações de emergência, deve se tomar decisões de forma rápida e precisa, verificando se há obstrução da via aérea do paciente, interrompendo o processo de queimadura, removendo as roupas que não estejam aderidas à pele e qualquer tipo de acessório, por fim, cobrindo as lesões com tecidos limpos. Se o acometimento da superfície for superior a $20 \%$ é necessário realizar acesso venoso no paciente. Se a extensão da queimadura não permitir o acesso com cateter através de pele íntegra,

RC: 92268

Disponível em: https://www.nucleodoconhecimento.com.br/saude/adultos-vitimas 
não deverá impedir que faça a introdução do cateter na pele queimada (AMERICAN COLLEGE OF SURGEONS, 2018).

A avaliação da extensão da queimadura pode ser realizada através da "regra dos nove", que corresponde a cálculos fundamentados em regiões de queimaduras de espessura parcial e total. O aspecto corporal do adulto é dividido em áreas anatômicas que refletem múltiplos de $9 \%$. Esse método permite estimar a dimensão das queimaduras com contornos ou disposição irregulares, sendo a ferramenta mais utilizada. Outra forma de analisar a amplitude das queimaduras é observá-la em áreas nobres/especiais como olhos, face, pescoço, mão, pé, grandes articulações, região inguinal e órgãos genitais (AMERICAN COLLEGE OF SURGEONS, 2018; MINISTÉRIO DA SAÚDE, 2012).

Após manejo das lesões iniciais é importante considerar as complicações que podem surgir durante a recuperação, no cenário intra-hospitalar ou após a alta do paciente. A equipe de cuidados deve monitorar o paciente para evitar possíveis infecções, que aumentariam o período de internação do paciente, favorecendo a proliferação de bactérias, precursoras de sepse e choque. Dessa forma, é imprescindível que a família seja informada a observar alterações potenciais, como a temperatura elevada, a frequência cardíaca elevada até mesmo em repouso, as modificações da ferida com presença de vermelhidão, pus e aumento de dor (SOCIEDADE BRASILEIRA DE QUEIMADURAS, 2021).

É importante que o paciente tenha acompanhamento psicológico e o apoio da família na sua caminhada de tratamento, já que grande parte dos pacientes queimados podem desencadear vários distúrbios físicos, que comprometem o equilíbrio emocional do paciente, já que na maioria dos casos pode ter alguma deformidade corporal (GIORDANI et al., 2016).

Diante disso, esta revisão de literatura tem como objetivo analisar e descrever a abordagem terapêutica em pacientes adultos vítimas de queimaduras, com base no grau da queimadura e o tratamento mais adequado.

RC: 92268

Disponível em: https://www.nucleodoconhecimento.com.br/saude/adultos-vitimas 


\section{DESENVOLVIMENTO}

\subsection{METODOLOGIA}

Esse estudo, refere-se a uma revisão bibliográfica do tipo sistemática integrativa de caráter retrospectivo, com abordagem qualitativa, com intuito descritivo de estudos nacionais e internacionais. Ademais, a natureza desta pesquisa enquadra-se como aplicada, tendo em vista que busca compreender a abordagem de pacientes vítimas de queimaduras e assim contribuir para o seu tratamento de forma mais adequada, evitando possíveis complicações.

A pesquisa foi feita durante o mês de maio de 2021, utilizando como meio de base de dados online o Portal da Biblioteca Virtual em Saúde (BVS) e seus sites aliados.

Diante disso, foi necessário para abordar no corpo de trabalho, descritores pertinentes que elucidem esta temática, por meio do vocabulário disponível no DeCS (Descritores em Ciências da Saúde), sendo essas "queimaduras", "cicatrização", "transplante de pele" "dor" e "analgésicos". Com isso, foram analisados 35 artigos encontrados no BVS e desses, 12 foram integrados na pesquisa. Foram utilizados como critérios de inclusão, artigos publicados em português, inglês e espanhol; artigos disponíveis na íntegra que retratam a temática referente à revisão integrativa e artigos do tipo ensaio clínico controlado. Além disso, foram excluídos os artigos que não estavam disponíveis na íntegra, duplicados e que não atendiam os objetivos da pesquisa. Para seleção dos artigos foi realizada leitura do título e do resumo para evidenciar os objetivos da pesquisa.

Diante disso, é válido salientar que a ordem da pesquisa não é de caráter prático, evidenciando, dessa forma, a dispensa de submissão ao Comitê de Ética em Pesquisa (CEP). Nesse quesito, foi configurada uma tabela contendo as principais informações dos artigos que foram revisados na pesquisa, sendo essas: título, autores, ano de publicação, país e os principais resultados.

RC: 92268

Disponível em: https://www.nucleodoconhecimento.com.br/saude/adultos-vitimas 


\subsection{RESULTADOS}

Tabela 1. Artigos analisados

\begin{tabular}{|c|c|c|c|}
\hline & Título & $\begin{array}{l}\text { Autores, } \\
\text { ano de } \\
\text { publicação } \\
\text { e país }\end{array}$ & Principais Resultados \\
\hline $\begin{array}{l}\text { Artigo } \\
\text { I }\end{array}$ & $\begin{array}{l}\text { Topical } \\
\text { treatment for } \\
\text { facial burns }\end{array}$ & $\begin{array}{l}\text { Hoogewerf } \\
\text { et al., } \\
2020 \text {, } \\
\text { Holanda }\end{array}$ & $\begin{array}{l}\text { Há evidências de certeza moderada de } \\
\text { que provavelmente há pouca ou nenhuma } \\
\text { diferença entre os agentes antimicrobianos } \\
\text { e os agentes não antimicrobianos no } \\
\text { tempo de cicatrização completa da ferida. } \\
\text { Agentes antimicrobianos tópicos podem } \\
\text { fazer pouca ou nenhuma diferença na } \\
\text { proporção de feridas completamente } \\
\text { curadas em comparação com agentes não } \\
\text { antimicrobianos tópicos. }\end{array}$ \\
\hline $\begin{array}{l}\text { Artigo } \\
\text { II }\end{array}$ & $\begin{array}{l}\text { The effect of a } \\
\text { hydrolyzed } \\
\text { collagen-based } \\
\text { supplement on } \\
\text { wound healing } \\
\text { in patients with } \\
\text { burn: A } \\
\text { randomized } \\
\text { double-blind } \\
\text { pilot clinical } \\
\text { trial. }\end{array}$ & $\begin{array}{l}\text { Bagheri } \\
\text { Miyab et } \\
\text { al., 2020, } \\
\text { Irã }\end{array}$ & $\begin{array}{l}\text { Os achados mostram que um suplemento } \\
\text { à base de colágeno hidrolisado poderia } \\
\text { melhorar a cicatrização de feridas, além de } \\
\text { reduzir o tempo de internação em } \\
\text { pacientes com queimaduras com } \\
\text { acometimento de } 20-30 \% \text {. }\end{array}$ \\
\hline
\end{tabular}

RC: 92268

Disponível em: https://www.nucleodoconhecimento.com.br/saude/adultos-vitimas 
Artigo Comparison of $\mathrm{Li}$ et al., No grupo experimental os escores de dor e III analgesic and 2019, ansiedade tiveram um desempenho anxiolytic Estados significativamente menor em relação ao effects of Unidos grupo controle. A titulação de Óxido Nítrico nitrous oxide in reduziu significativamente a dor e a burn wound ansiedade dos pacientes queimados com treatment: A mínimos efeitos colaterais.

single-blind

prospective

randomized

controlled trial.

Artigo Collagen Alet et al., O STGS (Enxerto de Pele de Espessura

IV

Parcial) teve sucesso em 28 pacientes e template in the França foi completamente rejeitado após 12 management of fullmeses em apenas um paciente. $O$ escore

thickness funcional médio aos 12 meses foi de wounds: a $76,8 / 100$ e o escore estético médio foi de prospective

multicentre study. 62,7/100. Sendo assim, o estudo mostra que o uso de um modelo de regeneração de colágeno é um procedimento seguro para a cobertura de feridas de espessura total.

Artigo An open-label, Holmes et Não foram observadas diferenças V prospective, al., 2019, significativas entre o tecido StrataGraft e randomized, Estados os locais de autoenxerto. O tratamento controlled, Unidos tecidual com StrataGraft reduziu a multicenter, phase $1 \mathrm{~b}$ study necessidade de autoenxerto e resultou no of StrataGraft fechamento adequado da ferida.

skin tissue

RC: 92268

Disponível em: https://www.nucleodoconhecimento.com.br/saude/adultos-vitimas 


\begin{tabular}{|c|c|c|c|}
\hline & $\begin{array}{l}\text { versus } \\
\text { autografting in } \\
\text { patients with } \\
\text { deep partial- } \\
\text { thickness } \\
\text { thermal burns. }\end{array}$ & & \\
\hline $\begin{array}{l}\text { Artigo } \\
\text { VI }\end{array}$ & $\begin{array}{l}\text { Negative } \\
\text { pressure } \\
\text { wound therapy } \\
\text { versus } \\
\text { microcurrent } \\
\text { electrical } \\
\text { stimulation in } \\
\text { wound healing } \\
\text { in burns. }\end{array}$ & $\begin{array}{l}\text { Ibrahim; } \\
\text { Waked; } \\
\text { Ibrahim, } \\
\text { 2019, Egito }\end{array}$ & $\begin{array}{l}\text { Houve significativa diminuição na área de } \\
\text { superfície ferida em todos os grupos. A } \\
\text { estimulação elétrica por microcorrente } \\
\text { (MES) obteve maior porcentagem média } \\
\text { na redução da superfície da ferida, } \\
\text { enquanto a terapia de feridas com pressão } \\
\text { negativa (NPWT) foi superior na redução } \\
\text { da contagem de colônias de feridas. } \\
\text { Ambos propiciaram o menor valor médio } \\
\text { para o tempo de permanência. }\end{array}$ \\
\hline $\begin{array}{l}\text { Artigo } \\
\text { VII }\end{array}$ & $\begin{array}{l}\text { Xenoenxerto } \\
\text { (pele da } \\
\text { Tilápia-do-Nilo) } \\
\text { e hidrofibra } \\
\text { com prata no } \\
\text { tratamento das } \\
\text { queimaduras } \\
\text { de II grau em } \\
\text { adultos / Nile } \\
\text { tilapia skin } \\
\text { xenograft } \\
\text { versus silver- } \\
\text { based } \\
\text { hydrofiber }\end{array}$ & $\begin{array}{l}\text { De } \\
\text { Miranda; } \\
\text { Brandt, } \\
2019 \text {, } \\
\text { Brasil }\end{array}$ & $\begin{array}{l}\text { Em relação à duração, o tratamento com a } \\
\text { pele da Tilápia do Nilo teve uma média } \\
\text { similar em relação à hidrofibra com prata } \\
\text { Aquacel Ag. Quanto ao relato de dor } \\
\text { durante a troca de curativos e após a } \\
\text { troca, não houve diferenças significativas } \\
\text { entre os dois métodos. Baseado no } \\
\text { estudo, pode-se afirmar que a pele de } \\
\text { Tilápia do Nilo é eficaz como curativo } \\
\text { biológico oclusivo. }\end{array}$ \\
\hline
\end{tabular}

RC: 92268

Disponível em: https://www.nucleodoconhecimento.com.br/saude/adultos-vitimas 
dressing in the

treatment of

second-degree

burns in adults

Artigo Comparative Manzoor et Em comparação com 0 tratamento VIII study of al., 2019, convencional, o tratamento com heparina conventional Estados reduziu o número de dias necessários para and topical Unidos a cicatrização da ferida e o consumo total heparin

treatment in second degree burn patients for burn analgesia and wound healing. de analgésicos em relação ao grupo convencional. Nos dois grupos nenhum paciente apresentou infecção da ferida, necrose cutânea, leucopenia, trombocitopenia, piora da função renal ou enzimas hepáticas anormais. Dessa forma, o tratamento com heparina tópica é placebol, sendo bem tolerado e sem maiores efeitos adversos.

Artigo Demonstration Holmes et As feridas tratadas pelos dois métodos IX of the safety al., 2019, eram semelhantes em tamanho médio, no and Estados entanto, no RECELL o uso médio de pele effectiveness Unidos foi reduzido em $32 \%$, estabelecendo of the RECELL $\circledast$

System combined with split-thickness superioridade no que tange às necessidades de pele do doador. Em combinação com o enxerto de pele de espessura dividida (STSG), o RECELL alcança cura de curto e longo prazo

RC: 92268

Disponível em: https://www.nucleodoconhecimento.com.br/saude/adultos-vitimas 


\begin{tabular}{|c|c|c|c|}
\hline & $\begin{array}{l}\text { meshed } \\
\text { autografts for } \\
\text { the reduction } \\
\text { of donor skin to } \\
\text { treat mixed- } \\
\text { depth burn } \\
\text { injuries. }\end{array}$ & & $\begin{array}{l}\text { comparável ao STSG padrão, enquanto o } \\
\text { uso de pele dos doadores é } \\
\text { significativamente menor. }\end{array}$ \\
\hline $\begin{array}{l}\text { Artigo } \\
X\end{array}$ & $\begin{array}{l}\text { Evaluation of } \\
\text { leap motion } \\
\text { control for } \\
\text { hand } \\
\text { rehabilitation in } \\
\text { burn patients: } \\
\text { An experience } \\
\text { in the dust } \\
\text { explosion } \\
\text { disaster in } \\
\text { Formosa Fun } \\
\text { Coast. }\end{array}$ & $\begin{array}{l}\text { Wu et al., } \\
2019 \text {, } \\
\text { Taiwan }\end{array}$ & $\begin{array}{l}\text { Segundo o estudo, o treinamento de Leap } \\
\text { Motion Control pode ajudar pacientes com } \\
\text { queimaduras nas mãos a diminuir a } \\
\text { cicatriz, melhorar a função da mão e } \\
\text { aumentar a amplitude do movimento } \\
\text { articular. }\end{array}$ \\
\hline $\begin{array}{l}\text { Artigo } \\
\text { XI }\end{array}$ & $\begin{array}{l}\text { Distinct } \\
\text { behavioral } \\
\text { response of } \\
\text { primary motor } \\
\text { cortex } \\
\text { stimulation in } \\
\text { itch and pain } \\
\text { after burn } \\
\text { injury. }\end{array}$ & $\begin{array}{l}\text { Thibaut et } \\
\text { al., } 2019, \\
\text { Irlanda }\end{array}$ & $\begin{array}{l}\text { Com base nos achados, parece haver um } \\
\text { importante efeito placebo durante a } \\
\text { simulação da estimulação transcraniana } \\
\text { por corrente contínua (ETCC) por prurido, } \\
\text { enquanto a ETCC M1 ativa parece } \\
\text { interromper os mecanismos } \\
\text { compensatórios sensoriais. A hipótese é } \\
\text { de que o prurido e a dor são mecanismos } \\
\text { complementares, mas distintos, de } \\
\text { adaptação após lesão sensorial periférica } \\
\text { após uma queimadura e, por isso, }\end{array}$ \\
\hline
\end{tabular}

RC: 92268

Disponível em: https://www.nucleodoconhecimento.com.br/saude/adultos-vitimas 
necessitam de tratamentos diferentes.

Artigo Efficacy and Jault et al., Em concentrações muito baixas, o PP1131 XII tolerability of a 2019, diminui a carga bacteriana em cocktail of Reino queimaduras em um ritmo mais lento do bacteriophages Unido que o tratamento padrão. No entanto, mais to treat burn estudos são necessários com \begin{tabular}{l|l} 
wounds & concentrações aumentadas em uma
\end{tabular} infected by amostra maior de participantes.

Pseudomonas aeruginosa (PhagoBurn): a randomised, controlled, double-blind phase $1 / 2$ trial.

Fonte: autores.

O manejo de pacientes adultos vítimas de queimaduras tem sofrido inúmeras transformações, desde o aperfeiçoamento de técnicas até o desenvolvimento de novos tratamentos. Dentre os mais inovadores, pode-se citar a utilização da pele de tilápia como curativo biológico, sobretudo para o tratamento de adultos vítimas de queimaduras de segundo grau, alternativa que já tem eficácia comprovada em diversos ensaios. Nesta técnica, a pele do animal é utilizada como enxerto no local da queimadura e atua como um curativo biológico, minimizando infecções oportunistas e a perda de líquidos, o que auxilia no desenvolvimento da reepitelização e da cicatrização (MIRANDA; BRANDT, 2018).

Ademais, em virtude do quadro de queimadura representar um ambiente propício para o desenvolvimento de bactérias, principalmente devido à temperatura em que as feridas se desenvolvem, técnicas mais complexas têm sido desenvolvidas a fim

RC: 92268

Disponível em: https://www.nucleodoconhecimento.com.br/saude/adultos-vitimas 
de reduzir a proliferação destes germes e acelerar o processo de cicatrização, o que pode ser exemplificado pelo tratamento de feridas com pressão negativa (NPWT) e pela estimulação elétrica por ação de microcorrente (MES). O primeiro, NPWT, tem se apresentado mais eficaz no processo de cicatrização e minimização da área queimada, atuando por meio de um processo de pressão negativa responsável por assegurar um ambiente úmido no local, ideal para estimular o desenvolvimento de novos tecidos e prevenir a desidratação de tais estruturas. O segundo, MES, devido à corrente elétrica, constitui um excelente bacteriostático, além de reduzir a propagação de microrganismos e estimular o aumento de fibroblastos, o que também contribui, assim, para o processo de cicatrização (IBRAHIM, 2019).

Por este viés, tem-se que a infecção por Pseudomonas aeruginosa constitui uma das principais causas de sepse em pacientes queimados, o que contribui em grande parte para o aumento do número de mortes. Diante disso, tem despontado o desenvolvimento de terapias promissoras com bacteriófagos para combater tais bactérias (PATRICK et al., 2018).

Outrossim, estudos têm evidenciado a suplementação de colágeno como um tratamento bastante promissor, tendo em vista que esta é uma proteína constituinte de ossos, dentes, músculos, tecido conjuntivo, pele e vários outros tecidos. Tal tratamento consiste na suplementação da ingestão oral de colágeno hidrolisado por, pelo menos, 4 semanas, a fim de facilitar a absorção pelo corpo já debilitado, o que favorece a regeneração de tecidos e a cicatrização, haja vista que há aumento da oferta de um dos componentes de tais estruturas orgânicas e diminui, consequentemente, o tempo de internação hospitalar (MIYAB et al., 2019).

Ainda no que tange à utilização de colágeno no manejo de pacientes queimados, estudo francês obteve sucesso nos desfechos relacionados ao uso de molde de regeneração de colágeno para cobertura de feridas, mesmo em pacientes considerados de alto risco. Tal procedimento consiste em uma bicamada formada por uma membrana de colágeno e outra de silicone. O silicone tem função de reforçar a camada construída e evitar que ela seja rompida, além de criar um

RC: 92268

Disponível em: https://www.nucleodoconhecimento.com.br/saude/adultos-vitimas 
ambiente úmido e favorável à formação do colágeno, o que, por conseguinte, predispõe à boa cicatrização. Cabe ressaltar que outro benefício da terapia é a possibilidade de cirurgiões não especializados realizarem com sucesso (ALET et al., 2019).

Além disso, dentre os tratamentos mais complexos e voltados para a recuperação das funções locomotoras, tem-se o movimento de salto. Este procedimento é utilizado para estimular os movimentos das mãos a fim de recuperar os movimentos finos dos pacientes que tiveram tal parte do corpo queimada (YAH-TING WU et al., 2018).

Dentre os tratamentos mais tradicionais, destaca-se o uso de pomadas nos locais de queimaduras, muitas com propriedades antimicrobianas, com o fito de prevenir infecções oportunistas, outras, com substâncias que estimulam o processo de regeneração tecidual, sendo ambas as propriedades comprovadamente importantes para a obtenção de resultados mais satisfatórios no processo de cura de queimados (HOOGEWERF et al., 2020).

Em 2019, estudo realizado por Holmes et al. (2019) comparou a eficácia do tratamento padrão, o autoenxerto, com o uso de tecido StrataGraft. Esse último tem como objetivo estimular as células autólogas a regenerar um epitélio estratificado escamoso. Durante a pesquisa foi observada, três meses depois do início do tratamento, a cicatrização e a cura das lesões nos tecidos que utilizaram o StrataGraft, sem complicações e infecções significativas após a execução do procedimento. Com base nesses resultados, conclui-se que o tratamento com tecido StrataGraft pode ser uma alternativa de tratamento para pacientes com queimaduras graves e, assim, diminuir a necessidade de autoenxerto.

Em outro experimento de Holmes et al. (2019) relacionado à abordagem de pacientes queimados, analisou-se nova alternativa de intervenção, reconhecida como Sistema RECELL. Este sistema configura um recurso terapêutico que desencadeia regeneração epidérmica em células autólogas com a finalidade de

RC: 92268

Disponível em: https://www.nucleodoconhecimento.com.br/saude/adultos-vitimas 
cicatrizar adequadamente e definitivamente as lesões em pacientes com queimadura. Ademais, é caracterizado por propiciar uma restauração imediata, resultando no aumento da sobrevida do paciente, diminuição da dor e das complicações infecciosas, além de reduzir o tempo de internação hospitalar. Cabe salientar que, neste estudo, 92\% dos indivíduos estudados obtiveram oclusão definitiva de suas feridas e utilizaram consideravelmente menos pele do doador.

Em uma comparação dos efeitos analgésicos e ansiolíticos do óxido nitroso $\left(\mathrm{N}_{2} \mathrm{O}\right)$ no tratamento de queimaduras, atestou-se que a titulação de $\mathrm{N}_{2} \mathrm{O}$ desencadeou efeitos analgésicos de importância considerável no manejo da dor. Os mesmos resultados foram apresentados em um ensaio clínico, em relação aos efeitos ansiolíticos. Nesse contexto notou-se que a titulação de $\mathrm{N}_{2} \mathrm{O}$ aliviou efetivamente a ansiedade dos pacientes. Quanto aos efeitos adversos, foram relatados em uma incidência abaixo de $10 \%$, sendo náuseas e vômitos os principais sintomas. Desse modo, o estudo reconhece que a titulação de $\mathrm{N}_{2} \mathrm{O}$ tem efeito analgésico eficaz e seguro para pacientes com queimadura em comparação ao uso de $50 \%$ de $\mathrm{N}_{2} \mathrm{O}$ (LI et al., 2019).

No que se refere às terapias farmacológicas, o uso de heparina tópica em pacientes com queimaduras de segundo grau apresentou resultados satisfatórios nos tratamentos em queimados, por possuir efeito quimiotático nas células endoteliais e estimular a neovascularização. Além disso, o anticoagulante tem um papel importante na indução dos mecanismos de reparo das lesões e na inibição de mediadores pró inflamatórios que agem nas terminações nervosas livres, o que gera analgesia. Evidenciou-se, portanto, que a heparina é responsável por controlar a dor, modular fases da cicatrização, diminuir o risco de descoloração da pele e, por fim, estabelecer uma cura mais rápida (MANZOOR et al., 2018).

Cabe destacar, deste modo, que artigo irlandês de 2018 descreveu a diferença entre a resposta comportamental do córtex motor primário no prurido e na dor após queimadura. A estratégia terapêutica abordada foi a Estimulação Transcraniana por Corrente Direta (ETCC), uma técnica de estimulação cerebral não invasiva que favorece a liberação de potencial de ação e altera a excitabilidade de RC: 92268

Disponível em: https://www.nucleodoconhecimento.com.br/saude/adultos-vitimas 
neurotransmissores, com o propósito de modular o limiar da dor. Neste estudo, observou-se nos pacientes a diminuição da ansiedade e, consequentemente, redução da dor e do prurido. Em vista disso, é notório a presença de um efeito placebo durante as estimulações. Em contrapartida, a ETCC, como já citado, modula o limiar sensorial da dor, podendo aumentar o prurido em pacientes queimados ou impedir o efeito placebo. Conclui-se, então, que a dor e o prurido devem ser tratados separadamente, mediante aplicação de manejos terapêuticos específicos para cada sintoma (THIBAUT et al., 2018).

\subsection{DISCUSSÃO}

No presente estudo estabeleceu-se parâmetros comparativos e discursivos, desenvolvendo técnicas no tratamento e cicatrização de pacientes com queimaduras, com a finalidade de buscar aperfeiçoamento nos procedimentos já utilizados. Iremos abordar de forma tópica cada um dos resultados, trazendo os benefícios elucidados, e discutindo possíveis implicações práticas.

De antemão, trazemos o uso da pele de tilápia, que mostrou bons resultados de cicatrização, evitou a contaminação da ferida por patógenos e se associou a um aumento de retenção hídrica na ferida. Foi observado também, redução da dor nos curativos dos pacientes submetidos a esse procedimento. Sendo importante ressaltar que, a pele de tilápia apresenta epitélio pavimentoso estratificado, e uma densa camada de colágeno o que condiz com sua morfologia semelhante à pele humana (JUNIOR et al., 2017; MIRANDA; BRANDT, 2019). Corroborando com NASCIMENTO et al., 2020, apresentando que a organização histomorfológica da pele de tilápia, tem maior aderência a pele, devido sua composição por colágeno tipo I na derme. Sendo assim, além de ser responsável pela estrutura e elasticidade da pele, auxilia nos fatores de crescimento dos fibroblastos, e por seguinte nos queratinócitos, contribuindo no fechamento da queimadura. Logo, conclui-se que, essa técnica pode ser uma boa alternativa em reparos teciduais de queimaduras de

RC: 92268

Disponível em: https://www.nucleodoconhecimento.com.br/saude/adultos-vitimas 
$2^{\circ}$ grau em adultos, sendo um tratamento eficaz de rápida cicatrização, baixo custo financeiro e indolor em sua terapia curativa.

Outrossim, o tratamento de feridas com pressão negativa, apresentou êxito na questão adaptativa e estética, em comparação à outros, entretanto, tem alto custo. Porém, consiste em uma técnica utilizada para queimaduras geralmente $3^{\circ}$ grau e queimaduras profundas, a qual isola a queimadura do meio externo à vácuo, e aplica uma pressão negativa sob uma esponja ou gaze, por um plástico que se conecta a um bomba aspirante, localizado dentro da queimadura. A finalidade é estimular a angiogênese, tecido de granulação e redução da resposta inflamatória, tudo isso por meio da sucção da bomba aspirante, tornando subatmosférica a pressão ali existente, evitando assim o acúmulo intersticial (LIMA; COLTRO; JÚNIOR, 2017). No entanto, os resultados mostram que esta técnica pode sim ser utilizada, desde que esteja associada a outra, desta maneira comprovando uma melhoria no tratamento, como, exposto por (WUNDERLICH et al., 2011) ao adicionar o uso de pressão negativa e a matriz de regeneração dérmica apresentaram resultados superiores, como baixo tempo de maturação da matriz e pouca perda de implante, em sua média parcial de $85 \%$ de benefício.

Conjuntamente COSTA et al(2010), submeteu um grupo de 12 pessoas adultas ao tratamento com microcorrente, e notou-se que a recuperação da queimadura apresentou uma grande evolução em relação a velocidade, associado a uma redução da dor. Destacando que, a microcorrente possui um efeito analgésico, sendo assim, a estimulação elétrica por ação de micro corrente (MES) em pacientes queimados tem sido benéfica em reparos teciduais de queimaduras.

MIYAB et al., 2019, trouxe o método de suplementação da ingestão oral de colágeno hidrolisado e a bicamada de colágeno, e de acordo com ALET et al., 2019 além de serem tratamentos bastantes promissores, que auxiliam na hidratação da pele, sustentação e firmeza, aumentam o número de aminoácidos, ajudando na regeneração de colágeno no organismo, portanto, assim certifica a reorganização tecidual. Contudo ainda há poucas evidências para que tais estudos se concretizem,

RC: 92268

Disponível em: https://www.nucleodoconhecimento.com.br/saude/adultos-vitimas 
assim como o tratamento de movimento em salto, mesmo que tal ainda seja de tamanha expressividade como já relatado por (YAH-TING WU et al., 2018), até então existem escassas evidências para correlacionar paralelamente os estudos.

De acordo com Hoogewerf et al. (2020), citado nos resultados anteriormente, o uso de antimicrobianos tópicos locais demonstrou-se satisfatórios na prevenção de infecções oportunistas locais. Ratificando esta afirmação, a Cartilha para tratamento de emergência das queimaduras (2012) considera que o uso de Sulfadiazina de prata 1\% (pomada com propriedades antimicrobianas) possui efeitos satisfatórios para o tratamento de adultos queimados.

Apesar de Holmes et al (2019) e Townsend et al. (2019) concordarem com a ideia de que o autoenxerto ainda se encontra como principal tratamento utilizado para adultos queimados, os mesmos, possuem opiniões distintas sobre o que poderia ser utilizado como tratamento opcional além do autoenxerto, já que o mesmo, muitas vezes não é suficiente para fechar toda a área queimada quando a ASCT excede 40\%. Enquanto Holmes et al (2019) assegura que o uso de tecido StrataGraft seria uma boa alternativa para o tratamento, pois estimula a regeneração tecidual, Townsend et al (2019) defende que a utilização de aloenxertos (pele de cadáver) e xenoenxertos (pele de porco) podem também ser utilizados como substitutos do autoenxerto, apesar de possuírem riscos de antigenicidade e limitação de disponibilidade, além de serem apenas tratamentos temporários. Townsend et al (2019) afirma também que, recentemente, foi aprovado pela U.S Food and Drug Administration, o uso de análogos dérmicos como o Integra ${ }^{\circledR}$ que apresentaram eficácia no fechamento completo imediato e tardio de queimaduras.

Outro tratamento comprovadamente eficaz por LI et al (2019) é o uso de óxido nitroso $\left(\mathrm{N}_{2} \mathrm{O}\right)$ como ansiolítico, ajudando com efeitos analgésicos em pacientes queimados. Em concordância com este pensamento, Li et al. (2013) afirma que o uso de óxido nitroso realmente é eficaz como ansiolítico e adiciona que o uso do mesmo, durante os cuidados com o curativo, é extremamente útil para analgesiar

RC: 92268

Disponível em: https://www.nucleodoconhecimento.com.br/saude/adultos-vitimas 
sem anestesiar o paciente, ou seja, tranquiliza-o sem realizar sedação, causando assim, a redução da dor.

Como exposto anteriormente nos resultados, a terapia farmacológica com uso de heparina tópica foi considerada benéfica para o tratamento de queimaduras de segundo grau, por estimular a vascularização local e a reformulação de células endoteliais (MANZOOR et al., 2018). Corroborando com este fato, estudos anteriores propõem que além de ser um tratamento satisfatório para o evidenciado previamente, também é utilizado como profilaxia de efeitos tromboembólicos (MINISTÉRIO DA SAÚDE, 2012).

A utilização de Estimulação Transcraniana por Corrente Direta (ETCC) com objetivo de modular a dor e assim diminuí-la em pacientes queimados, defendida por Thibaut et al (2018) e o uso do Sistema RECELL como forma de regeneração epidérmica, defendido por Holmes et al (2019) apesar de serem tratamentos importantes e inovadores, ainda não há muitos estudos sobre os assuntos, dificultando comparações em que haja concordância ou discordância em literaturas vigentes.

Uma das principais limitações deste estudo, que tem como objetivo investigar os tratamentos existentes atualmente para adultos queimados seria a inacessibilidade dos mesmos. Muitos tratamentos encontram-se somente em hospitais de rede privada, somente em grandes centros, dificultando, assim, sua utilização na maioria dos pacientes, e quando no SUS ainda não é oferecida esta medida terapêutica .Este fato, cria também, um impasse para os novos estudos que procuram a aplicação deste tratamento, já que é um método simples, não invasivo e pouco custo financeiro, deve ser acessível a toda população, pois como o (DO NASCIMENTO et al., 2020) cita em seu artigo que o tratamento realizado pela rede pública brasileira é constituído basicamente de pomada de sulfadiazina de prata, contudo medidas são necessárias para resolver este impasse.

Por outro lado, é evidente que o uso da pele de tilápia, como foi exposto anteriormente, este tipo de tratamento é centralizado no Brasil, portanto, há regiões

RC: 92268

Disponível em: https://www.nucleodoconhecimento.com.br/saude/adultos-vitimas 
que apresentam esse tipo de conduta que são ofertadas em redes privadas para seus pacientes, enquanto outras, não o apresentam (DO NASCIMENTO et al., 2020).

Os tratamentos abordados nos resultados e ratificados com outras literaturas vigentes na discussão, permitem que haja boas perspectivas sobre o que foi tratado neste estudo. Espera-se que, quanto mais reconhecido os estudos sobre os diferentes tipos de tratamentos para adultos queimados, como este, se tornarem atuais e acessíveis, mais será utilizado como conduta para pacientes adultos queimados, melhorando a qualidade de vida durante o tratamento e até mesmo o tempo de internação em alguns casos.

Como abordado acima durante a discussão, ainda há estudos que possuem pouca literatura atual que comprovem alguns determinados tratamentos para pacientes queimados. Ponderando esse assunto, é necessário realizar mais pesquisas sobre estas condutas, como por exemplo sobre a utilização de Estimulação Transcraniana por Corrente Direta (ETCC). Estudos atuais abordados durante os resultados afirmam que este tratamento é eficaz para tratar de pacientes adultos queimados, porém, não há muitos outros estudos que concordem ou discordem desta afirmativa, o que ratifica a ideia de necessidade de mais estudos na área. Além disso, uma nova pesquisa poderia abordar o real motivo da causa de alguns tratamentos já comprovadamente eficazes por inúmeros estudos ainda não serem utilizados de forma generalizada, como é o caso da pele de tilápia.

Urge, portanto, que o Governo Federal em parceria com o ministério da saúde, cooperarem e invistam financeiramente em estudos que comprovem a eficácia de curativos em pacientes com queimaduras, pois é evidente a necessidade que um tratamento eficaz a ser oferecido no Sistema Único de Saúde (SUS), pois, segundo a Organização Mundial de Saúde (OMS) as causas de queimaduras são validadas como um trauma de alta complexidade, que apresentam altas taxas de mortalidade, podendo serem consideradas a quinta causa de morte acidental no mundo (CARVALHO et al., 2020), contudo, torna-se necessário que tais medidas sejam

RC: 92268

Disponível em: https://www.nucleodoconhecimento.com.br/saude/adultos-vitimas 
tomadas.Com finalidade para que maior número de quantidade de pacientes tratados e baixa morbidade entre eles, sendo necessário que, seja também disponibilizado mais opções de tratamento nas Unidades Básicas de Saúde (UBS) para que estes pacientes queimados não sejam transferidos para unidade de alta complexidade, por fim trazendo maior taxa de recuperação entre os pacientes adultos queimados.

\section{CONSIDERAÇÕES FINAIS}

A análise de estudos relacionados à abordagem terapêutica de pacientes adultos vítimas de queimaduras permite constatar, de maneira comparativa, a abrangência de condutas clínico-cirúrgicas de eficácia comprovada no manejo destes indivíduos.

Destaca-se, neste sentido, o uso da pele de tilápia, técnica que propiciou bons resultados no que se refere à cicatrização adequada e reepitelização do tecido lesado. Ademais, no que tange à evolução das técnicas de catalisação da cicatrização e prevenção de eventos infecciosos, tem se sobressaído a adoção do tratamento de feridas com pressão negativa e estimulação elétrica por ação de microcorrentes, assim como a suplementação oral e utilização de curativos formulados com colágeno.

No que concerne ao manejo cirúrgico, cabe realce a utilização do StrataGraft como alternativa à aplicação de autoenxertos e a regeneração epidérmica em células autólogas estimulada pelo Sistema RECELL.

\section{REFERÊNCIAS}

ALET, Jean-Maxime et al. Collagen regeneration template in the management of fullthickness wounds: a prospective multicentre study. Journal of Wound Care, France, $\begin{array}{lllllll}\text { v. } 28, \quad \text { ed. } 8, \quad 22-30, & \text { p. } & \text { ago. }\end{array}$ https://doi.org/10.12968/jowc.2019.28.sup8.s22. Disponível em:

RC: 92268

Disponível em: https://www.nucleodoconhecimento.com.br/saude/adultos-vitimas 
https://pesquisa.bvsalud.org/portal/resource/pt/mdl-31393780. Acesso em: 12 maio 2021

AMERICAN COLLEGE OF SURGEONS. Advanced Trauma Life Suport - ATLS. 8. ed. [S. l.: s. n.], 2018.

BAGHERI MIYAB, Katayoun et al. The effect of a hydrolyzed collagen-based supplement on wound healing in patients with burn: A randomized double-blind pilot clinical trial. Burns, Iran, v. 46, ed. 1, p. 156-163, February 2020. DOI https://doi.org/10.1016/j.burns.2019.02.015. Disponível em: https://pesquisa.bvsalud.org/portal/resource/pt/mdl-31859087. Acesso em: 12 maio 2021.

BORGES DE MIRANDA, Marcelo José; TEIXEIRA BRANDT, Carlos. Nile tilapia skin xenograft versus silver-based hydrofiber dressing in the treatment of second-degree burns in adults. Brazilian Journal of Plastic Surgery, Brazil, v. 34, ed. 1, 2019. DOI DOI: 10.5935/2177-1235.2019RBCP0012. Disponível em: https://pesquisa.bvsalud.org/portal/resource/pt/biblio-994550. Acesso em: 12 maio 2021.

CARVALHO, Bárbara Dryelle Penha; MELCHIOR, Lorena Morena Rosa; SANTOS, Erika Rodrigues dos; MARGARIDA, Mykaella Cristina Araujo; COSTA, Camila de Sá Nunes; PORTO, Priscilla de Souza. Perfil epidemiológico de pacientes vítimas de queimadura atendidos em um hospital público de urgência do estado de Goiás. Revista Brasileña de Queimaduras, Goiânia - GO, v. 18, n. 3, p. 167-172, 24 ago. 2020. Disponível em: http://www.rbqueimaduras.com.br/how-to-cite/478/pt-BR. Acesso em: 4 jun. 2021.

COSTA, Sharin Costa, Angela Freitas, Carina Santos, Ft., M.Sc. et al. Efeitos da aplicação de microcorrente no processo de reparo tecidual de queimaduras. Fisioterapia Brasil , [S. I.], ano 2010, v. 11, n. 1, p. 103-108, 8 mar. 2010. Disponível

RC: 92268

Disponível em: https://www.nucleodoconhecimento.com.br/saude/adultos-vitimas 
em:file://C:/Users/55949/OneDrive/\%C3\%81rea\%20de\%20Trabalho/1350Texto\%20do\%20Artigo-8293-1-10-20171117.pdf. Acesso em: 1 out. 2017.

DO NASCIMENTO, Andreia Braga; MORAIS, Fablenia de Sá; BEZERRA, Jaqueline Souza; SILVA, Macerlane de Lira; OLIVEIRA, Geane Silva; BEZERRA, Yuri Charllub Pereira. O USO DA PELE DE TILÁPIA NO TRATAMENTO DE QUEIMADURAS. Temas em Saúde - Edição Especial, João Pessoa, p. 128-143, 2020. DOI 10.29327/216797.1.1-6. Disponível em: https://temasemsaude.com/wpcontent/uploads/2020/05/art-06-FSM.pdf. Acesso em: 3 jun. 2021.

GIORDANI, Annecy Tojeiro et al. Complicações em pacientes queimados: revisão integrativa. Revista Eletrônica Gestão e Saúde, n. 2, p. 535-548, 2016.

HOLMES, James $\mathrm{H}$ et al. An open-label, prospective, randomized, controlled, multicenter, phase $1 \mathrm{~b}$ study of StrataGraft skin tissue versus autografting in patients with deep partial-thickness thermal burns. Burns, United States of America, v. 45, ed. 8, p. 1749-1758, 12 jul. 2019. DOI https://doi.org/10.1016/j.burns.2019.07.021. Disponível em: https://pesquisa.bvsalud.org/portal/resource/pt/mdl-31416637. Acesso em: 12 maio 2021.

HOLMES, James $\mathrm{H}$ et al. Demonstration of the safety and effectiveness of the RECELL System combined with split-thickness meshed autografts for the reduction of donor skin to treat mixed-depth burn injuries. Burns, United States of America, v. 45, ed. 4, p. 772-782, 2019. DOI https://doi.org/10.1016/j.burns.2018.11.002. Disponível em: https://pesquisa.bvsalud.org/portal/resource/pt/mdl-30578048. Acesso em: 12 maio 2021.

HOOGEWERF, Cornelis $\mathrm{J}$ et al. Tropical treatment for facial burns. Cochrane Database of Systematic Reviews, Netherlands, ed. 7, 2020. DOI https://doi.org/10.1002/14651858.cd008058.pub3. Disponível em: https://pesquisa.bvsalud.org/portal/resource/pt/mdl-32725896. Acesso em: 12 maio 2021.

RC: 92268

Disponível em: https://www.nucleodoconhecimento.com.br/saude/adultos-vitimas 
IBRAHIM, Zizi M.; WAKED, Instar S.; IBRAHIM, Olfat. Negative pressure wound therapy versus microcurrent electrical stimulation in wound healing in burns. Journal of Wound Care, Egypt, v. 28, n. 4, 11 abr. 2019. DOI https://doi.org/10.12968/jowc.2019.28.4.214. Disponível em: https://pesquisa.bvsalud.org/portal/resource/pt/mdl-30975055. Acesso em: 12 maio 2021.

JAULT, Patrick et al. Efficacy and tolerability of a cocktail of bacteriophages to treat burn wounds infected by Pseudomonas aeruginosa (PhagoBurn): a randomised, controlled, double-blind phase 1/2 trial. The Lancet Infectious Diseases, France, v. 19, ed. 1, p. 35-45, 1 jan. 2019. DOI https://doi.org/10.1016/s1473-3099(18)30482-1. Disponível em: https://pesquisa.bvsalud.org/portal/resource/pt/mdl-30292481. Acesso em: 12 maio 2021.

JUNIOR, E. M. L. et al. Uso da pele de tilápia (Oreochromis niloticus), como curativo biológico oclusivo, no tratamento de queimaduras. Rev. Bras Queimaduras, v.16, n.1, p.10-17, 2017

LI , Lin et al. Comparison of analgesic and anxiolytic effects of nitrous oxide in burn wound treatment. US National Library of Medicine National Institutes of Health, China, v. 98, ed. 51, 20 dez. 2019. DOI https://dx.doi.org/10.1097\%2FMD.0000000000018188. Disponível em: https://pesquisa.bvsalud.org/portal/resource/pt/mdl-31860965. Acesso em: 12 maio 2021.

LI, Yu-Xiang et al. Nitrous oxide-oxygen mixture during burn wound dressing: a double-blind randomized controlled study. CNS Neurosci Therapeutics, [s. I.], 2013. DOI 10.1111/cns.12061. Disponível em: https://onlinelibrary.wiley.com/doi/full/10.1111/cns.12061. Acesso em: 5 jun. 2021.

LIMA, RENAN VICTOR KÜMPEL SCHMIDT; COLTRO, PEDRO SOLER; JÚNIOR, JAYME ADRIANO FARINA. Terapia por pressão negativa no tratamento de feridas

RC: 92268

Disponível em: https://www.nucleodoconhecimento.com.br/saude/adultos-vitimas 
complexas. Revista do Colégio Brasileiro de Cirurgiões, São Paulo - SP, p. 8193, 10 jul. 2017. DOI 10.1590/0100-69912017001001. Disponível em: https://www.scielo.br/j/rcbc/a/W6qy4BFN9DkdTRsGy6jrfkk/?lang=en. Acesso em: 2 jun. 2021.

MANZOOR, Sobia et al. Comparative study of conventional and topical heparin treatment in second degree burn patients for burn analgesia and wound healing. Burns , Pakistan, v. 45, ed. 2, p. 379-386, March 2019. DOI https://doi.org/10.1016/j.burns.2018.05.010. Disponível em: https://pesquisa.bvsalud.org/portal/resource/pt/mdl-30529119. Acesso em: 12 maio 2021.

MINISTÉRIO DA SAÚDE (Brasil). Secretaria de Atenção à Saúde. Cartilha para tratamento de emergência das queimaduras. [S. I.: s. n.], 2012. Disponível em: https://bvsms.saude.gov.br/bvs/publicacoes/cartilha_tratamento_emergencia_queim aduras.pdf. Acesso em: 30 jun. 2021

MIRANDA, MARCELO JOSÉ BORGES DE; BRANDT, CARLOS TEIXEIRA. Xenoenxerto (pele da Tilápia-do-Nilo) e hidrofibra com prata no tratamento das queimaduras de II grau em adultos. Revista Brasileira de Cirurgia Plástica, [S. I.], v. 34, p. 79-85, 30 jul. 2019. DOI 10.5935/2177-1235.2019RBCP0012. Disponível em: http://www.rbcp.org.br/details/2349/pt-BR/xenoenxerto--pele-da-tilapia-do-nilo-e-hidrofibra-com-prata-no-tratamento-das-queimaduras-de-ii-grau-em-adultos. Acesso em: 2 jun. 2021.

SOCIEDADE BRASILEIRA DE CIRURGIA PLÁSTICA. Queimados: Diagnóstico e Tratamento Inicial. São Paulo: [s. n.], 2008.

SOCIEDADE BRASILEIRA DE QUEIMADURAS. PRIMEIROS CUIDADOS ÀS QUEIMADURAS. [S. I.: s. n.], 2021.

RC: 92268

Disponível em: https://www.nucleodoconhecimento.com.br/saude/adultos-vitimas 
THIBAUT, Aurore et al. Distinct behavioral response of primary motor cortex stimulation in itch and pain after burn injury. Neuroscience Letters, United States of America, v. $690, \quad$ p. $89-94,18$ jan. 2019. DOI https://doi.org/10.1016/j.neulet.2018.10.013. Disponível em: https://pesquisa.bvsalud.org/portal/resource/pt/mdl-30312754. Acesso em: 12 maio 2021.

TOWNSEND, Courtney M.; BEAUCHAMP, R. Daniel; EVERS, B. Mark; MATTOX, Kenneth L. Sabiston tratado de cirurgia : a base biológica da prática cirúrgica moderna. 20. ed. Rio de Janeiro: Elsevier Editora Ltda., 2019.

WU, Yah-Ting et al. Evaluation of leap motion control for hand rehabilitation in burn patients: An experience in the dust explosion disaster in Formosa Fun Coast. Burns , Taiwan, v. 45, ed. 1, p. 157-164, February 2019. DOI https://doi.org/10.1016/j.burns.2018.08.001. em: https://pesquisa.bvsalud.org/portal/resource/pt/mdl-30322737. Acesso em: 12 maio 2021.

WUNDERLICH, B. L. ; B. M.; J. A.; E. J. ; R.F.; Maurício José Lopes. et al. Curativo com pressão negativa e matriz de regeneração dérmica: uma nova opção de tratamento para feridas extensas. Rev. Bras Queimaduras, [S. I.], p. 78-84, 4 nov. 2011.

Enviado: Julho, 2021.

Aprovado: Julho, 2021.

RC: 92268

Disponível em: https://www.nucleodoconhecimento.com.br/saude/adultos-vitimas 